\title{
Studies on Growth and Carbofuran Degredation Potential of Bacterial Isolates
}

\author{
M. Nafeesa*, K. Ramaraju, S. Kuttalam and P. Doraisamy \\ Tamil Nadu Agricultural University, Coimbatore \\ Malikapparambu, Alathur (PO), Palakkad - 678541, Kerala
}

\begin{abstract}
Studies were conducted at Agricultural College and Research Institute, Tamil Nadu Agricultural University, Coimbatore to examine the growth and carbofuran degradation potential of bacterial isolates viz., CF-1, CF-2, CF-3, CF-4 and CF-7. Among them CF-7 recorded highly significant growth in carbofuran amended Mineral Salt Medium exhibiting an optical density of 0.557 at 600 $\mathrm{nm}$ after $48 \mathrm{~h}$ of incubation, which was followed by CF-1 (0.395), CF-4 (0.252), CF-3 (0.210) and CF-2 (0.197). In the recovery study, mean recoveries of carbofuran in MSM were 81.25, 87.36 and 83.96 per cent, respectively for the three fortification levels viz., $0.25,0.5$ and $1 \mathrm{ppm}$. The highest reduction in carbofuran concentration was recorded in MSM inoculated with CF-7 (reduced to $\mathbf{1 7 . 7 1} \%$ as compared to $\mathbf{5 0 . 2 5 \%}$ in the control).
\end{abstract}

Key words : Bacterial isolates, Carbofuran degradation potential

Carbofuran (2, 3-dihydro-2, 2-dimethyl-7benzofuranyl methylcarbamate), one of the widely used agrochemical and is a broad spectrum systemic insecticide, miticide and nematicide. It was developed by Niagara Chemical Division of FMC Corporation in 1967 under the trade name Furadan. It is a potent inhibitor of cholinesterase as a result, is found to be highly toxic to mammals. Oral LD50 of $2 \mathrm{mg} / \mathrm{kg}$ has been recorded in mice (Fahmy, 1970). Therefore, it can be potentially hazardous as a result of accidental spills and runoff from areas of application. Due to extensive and diverse use and unintentional discharge into the environment, carbofuran has become one of the most frequently detected pesticides in water resources. Accumulation of carbofuran and its metabolites in the environment could potentially pose health hazards (Chaudhry et al., 2002). The study of microbial adaptation to pesticides and other environmental contaminants is leading to opportunities to harness microorganisms for cleanup of polluted soil and water. Hence, this study was conducted with an objective to assess the growth and degradation potential of carbofuran degrading bacterial isolates in the artificial media provided with carbofuran as a sole source of carbon.

\section{Material and Methods}

Technical grade carbofuran with 99.3 per cent purity obtained from FMC India Private Limited, Bengaluru was used for this study. Carbofuran stock solution of $1000 \mathrm{ppm}(0.101 \mathrm{~g}$ dissolved in $100 \mathrm{ml}$ of acetone) was prepared for supplementing the MSM. Another carbofuran stock solution of 1000 ppm $(0.101 \mathrm{~g}$ dissolved in acetonitrile and diluted to $100 \mathrm{ml}$ ) was prepared and five working standards at concentration levels of $0.1,0.25,0.5,1$ and $2.5 \mu \mathrm{g} /$ $\mathrm{ml}$ were prepared by appropriate dilution of the 1000 $\mu \mathrm{g} / \mathrm{ml}$ stock standard solution with acetonitrile for calibrating the HPLC for residue analysis.

Five bacterial isolates, isolated and purified from the carbofuran enrichment cultures (Nafeesa. M, 2009) were selected for the study i.e. CF-1, CF-2, CF-3, CF-4 and CF-7. Mineral Salt Medium (MSM) $\left(\mathrm{K}_{2} \mathrm{HPO}_{4}-4.8 \mathrm{~g}, \mathrm{KH}_{2} \mathrm{PO}_{4}-1.2 \mathrm{~g}, \mathrm{NH}_{4} \mathrm{NO}_{3}-1.0 \mathrm{~g}\right.$, $\mathrm{MgSO}_{4}-0.2 \mathrm{~g}, \mathrm{Ca}\left(\mathrm{NO}_{3}\right)_{2}-0.4 \mathrm{~g}$ and $\mathrm{Fe}_{2}\left(\mathrm{SO}_{4}\right)_{3}-$ $0.001 \mathrm{~g}$ per litre) provided with carbofuran as the sole source of carbon $\left(50 \mu \mathrm{g} \mathrm{ml}^{-1}\right)$ was used. Before supplementing the media with carbofuran, the media was sterilized by autoclaving it at $1.2 \mathrm{Kg} \mathrm{cm}^{-2}$ pressure for $20 \mathrm{~min}$. Two and half $\mathrm{ml}$ of the stock solution with acetone was added into the sterilized conical flasks. Allow the acetone portion to evaporate fully at room temperature to ensure the growth of the microorganisms in the media. Fifty $\mathrm{ml}$ of the MSM was aseptically transferred in to the conical flasks, which were already supplemented with carbofuran. The inoculums were prepared by growing the five isolates separately in $50 \mathrm{ml}$ of MSM supplemented with carbofuran. After inoculating the media with appropriate cultures, the flasks were kept overnight on a rotary shaker at $30^{\circ} \mathrm{C}$ and at $200 \mathrm{rpm}$. All inoculations were made at one per cent level, i.e. the equivalent of one $\mathrm{ml}$ of inoculum to $100 \mathrm{ml}$ of liquid media $(0.5 \mathrm{ml}$ for $50 \mathrm{ml}$ of the media) (Singh et al., 2004). The flasks were incubated at room temperature $\left(30 \pm 2^{\circ} \mathrm{C}\right)$.

Five isolates were inoculated into $250 \mathrm{ml}$ conical flasks containing $50 \mathrm{ml}$ of the MSM supplemented with carbofuran as carbon source. A control (without the bacterial inoculum) was also maintained in the experiment. There were $\mathrm{s}$ ix treatments viz., CF1, CF-2, CF-3, CF-4 and CF-7 and control. Each treatment was replicated trice. In each replicate six

*Corresponding author email: nafiento@gmail.com 
duplicate flasks were maintained to study the growth of the isolate and to estimate the carbofuran residue level in the media.

Growth of the isolates in the medium were estimated by measuring the increase in turbidity of the medium using UV/VIS spectrometer (Lambda $\mathrm{Bio}^{\circledR}$, PERKIN ELMER GmbH, Germany) at $600 \mathrm{~nm}$. Five $\mathrm{ml}$ suspension from the incubated flasks (duplicated flasks) were removed for microbial analysis. The readings were taken at four hour intervals for four days from the day of inoculation. Control (MSM without inoculum) was kept as blank while taking the readings.

Sampling and Residue estimation in the media was done by combining and following the methods adopted by Ramanad et al. (1988), Yan et al. (2007) and Talebi and Walker, (1993). Samples were taken from the duplicate flasks at desired intervals i.e. 0 , $1,2,4,8$ and $15 \mathrm{DAl}$ after homogenization of the media by placing the flasks in a shaker (Orbitech, BVN, Instrument Pvt. Ltd., Chennai) for one hour at $150 \mathrm{rpm}$. Five $\mathrm{ml}$ of homogenized media from each replicated flasks were removed aseptically and pooled. From the pooled suspension, five $\mathrm{ml}$ was taken as a representative sample for the extraction of carbofuran residue. Fifty $\mathrm{ml}$ of dichloromethane was added to the five $\mathrm{ml}$ portion of MSM containing carbofuran taken in a separating funnel. The mixture was vigorously shaken for $10 \mathrm{~min}$ and left to stand until phase separation took place. The dichloromethane layer (bottom layer) was filtered through anhydrous sodium sulphate in a funnel fluted with Whatman No.1 filter paper. The samples were extracted twice. The extracts were combined and evaporated on a rotary evaporator at $40^{\circ} \mathrm{C}$ under vacuum near to dryness. The residue was dissolved in five $\mathrm{ml}$ of acetonitrile. The prepared samples were diluted to 50 times (200 $\mu \mathrm{l}$ of the sample to $10 \mathrm{ml}$ with acetonitrile) before injection. Dilutions of the samples were done to get a lower concentration to protect the HPLC column.

Recovery studies and residue analysis was done by using HPLC - UV (Shimadzu LC 20 AT, Shimadzu India Pvt. Ltd., Mumbai.). The operational parameters (Column - RP $18(10 \mu \mathrm{m})(25 \times 3.2$ i. d), Mobile phase - Acetonitrile:Water $(60: 40 \mathrm{v} / \mathrm{v})$, Flow rate $-1 \mathrm{ml} /$ min, Sample Injection Volume - $20 \mu \mathrm{l}$ ) were fixed by referring and modifying the parameters used by Talebi and Walker, (1993) and Farahani et al. (2007). The HPLC was calibrated using five working standard solutions of carbofuran at concentration levels of 0.1 , $0.25,0.5,1$ and $2.5 \mu \mathrm{g} / \mathrm{ml}$.

For recovery studies, fortifications were done in three concentration levels $(0.25,0.5$ and $1 \mathrm{ppm})$. Fifty $\mathrm{ml}$ of the culture medium was fortified with carbofuran in three above mentioned levels. After the additions of the chemical, the media was homogenized by placing it in a shaker for one hour. Five $\mathrm{ml}$ portion of the culture media was taken as a representative sample for extraction. The standard solutions were loaded after conditioning and recoveries were calculated from the chromatogram of the standard solution. Recovery studies were conducted in triplicate at three concentration level $(0.25,0.5$ and $1 \mathrm{ppm})$. The amount of insecticide residue recovered was measured by comparing the sample response with the response of standard in the HPLC chromatogram by using the formula (Kohout, 1974).

Statistical scrutinies of the results were made as per the method described by Panse and Sukhatmi (1985). Dissipation curves of carbofuran in different treatments were fit as suggested by Nigg and Stamper (1980). Other statistical parameters like confidence intervals for intercept (a), slope of regression line (b), half life $\left(T_{0.5}\right)$ and coefficient of determination $\left(r^{2}\right)$ were obtained following the procedures described by Timme et al. (1986). The different functions were worked out for the residue data to fit the dissipation curves as per Regupathy and Dhamu (2001). The best fit model for control and for each isolate was selected by comparing the correlation coefficient values for different functions and modified $r^{2}$.

\section{Results and Discussion}

The degradation potential of carbofuran degrading isolates was estimated by measuring the growth of the isolates and by recording the reduction in carbofuran residues in the MSM. Growth of the isolates in the media provided with $50 \mu \mathrm{g}$ of carbofuran as the sole source of carbon is listed in Table 1.

Table 1. Growth of the carbofuran degrading bacterial isolates in MSM provided with $50 \mu \mathrm{g}$ of carbofuran as the sole source of carbon

\begin{tabular}{cccccc}
\hline \multirow{2}{*}{$\begin{array}{c}\text { Time after } \\
\text { inoculation } \\
\text { (Hours) }\end{array}$} & \multicolumn{4}{c}{ Growth of the isolates at OD $600 \mathrm{~nm}$} \\
\cline { 2 - 6 } & CF-1 & CF-2 & CF-3 & CF-4 & CF-7 \\
\hline 0 & 0.027 & 0.025 & 0.021 & 0.028 & 0.034 \\
8 & 0.039 & 0.030 & 0.022 & 0.024 & 0.058 \\
16 & 0.053 & 0.042 & 0.039 & 0.059 & 0.172 \\
24 & 0.098 & 0.079 & 0.068 & 0.072 & 0.389 \\
32 & 0.134 & 0.082 & 0.097 & 0.078 & 0.523 \\
40 & 0.298 & 0.193 & 0.148 & 0.203 & 0.538 \\
48 & 0.395 & 0.197 & 0.210 & 0.252 & 0.557 \\
56 & 0.397 & 0.201 & 0.297 & 0.269 & 0.559 \\
64 & 0.401 & 0.205 & 0.299 & 0.271 & 0.575 \\
72 & 0.413 & 0.211 & 0.302 & 0.275 & 0.576 \\
80 & 0.417 & 0.223 & 0.305 & 0.282 & 0.579 \\
88 & 0.425 & 0.225 & 0.309 & 0.293 & 0.588 \\
96 & 0.429 & 0.231 & 0.318 & 0.299 & 0.589 \\
\hline
\end{tabular}

The isolate CF-7 identified as Bacillus sp. recorded a significant growth by giving an optical density of 0.557 at $600 \mathrm{~nm}$ after $48 \mathrm{~h}$ of incubation, 
which was followed by CF-1 (0.395), CF-4 (0.252), CF-3 (0.210) and CF-2 (0.197). The mean recoveries of carbofuran in MSM were $81.25,87.36$ and 83.96 per cent, respectively for the three fortification levels of $0.25,0.5$ and $1 \mathrm{ppm}$. Concentrations of the carbofuran present in the MSM after incubation with

Table 2. Concentrations of the carbofuran present in the MSM after the inoculation of different carbofuran degrading bacterial isolates

\begin{tabular}{|c|c|c|c|c|c|c|}
\hline \multirow{2}{*}{$\begin{array}{l}\text { Days after } \\
\text { inoculation }\end{array}$} & \multicolumn{6}{|c|}{ Residue level $(\mu \mathrm{g} / \mathrm{ml})$} \\
\hline & Control & CF-1 & CF-2 & CF-3 & CF-4 & CF-7 \\
\hline 0 & 49.62 & 57.71 & 45.14 & 44.93 & 49.79 & 58.93 \\
\hline 1 & $\begin{array}{c}45.21 \\
(90.24)\end{array}$ & $\begin{array}{c}41.34 \\
(71.64)\end{array}$ & $\begin{array}{c}37.95 \\
(84.08)\end{array}$ & $\begin{array}{c}34.08 \\
(75.84)\end{array}$ & $\begin{array}{c}44.23 \\
(88.84)\end{array}$ & $\begin{array}{c}32.00 \\
(54.30)\end{array}$ \\
\hline 2 & $\begin{array}{c}43.66 \\
(87.98)\end{array}$ & $\begin{array}{c}30.20 \\
(52.33)\end{array}$ & $\begin{array}{c}35.25 \\
(78.08)\end{array}$ & $\begin{array}{c}30.94 \\
(68.86)\end{array}$ & $\begin{array}{c}36.05 \\
(74.40)\end{array}$ & $\begin{array}{c}23.58 \\
(40.01)\end{array}$ \\
\hline 4 & $\begin{array}{c}38.72 \\
(78.03)\end{array}$ & $\begin{array}{c}30.00 \\
(51.98)\end{array}$ & $\begin{array}{c}32.00 \\
(70.88)\end{array}$ & $\begin{array}{c}26.00 \\
(57.86)\end{array}$ & $\begin{array}{c}33.21 \\
(66.71)\end{array}$ & $\begin{array}{c}22.98 \\
(39.00)\end{array}$ \\
\hline 8 & $\begin{array}{c}33.15 \\
(66.81)\end{array}$ & $\begin{array}{c}29.37 \\
(50.89)\end{array}$ & $\begin{array}{c}26.24 \\
(58.35)\end{array}$ & $\begin{array}{c}24.89 \\
(55.39)\end{array}$ & $\begin{array}{c}28.95 \\
(58.15)\end{array}$ & $\begin{array}{c}22.00 \\
(37.33)\end{array}$ \\
\hline 15 & $\begin{array}{c}24.93 \\
(50.25)\end{array}$ & $\begin{array}{c}18.72 \\
(32.44)\end{array}$ & $\begin{array}{c}21.31 \\
(47.20)\end{array}$ & $\begin{array}{c}21.64 \\
(48.16)\end{array}$ & $\begin{array}{c}20.91 \\
(41.99)\end{array}$ & $\begin{array}{c}10.43 \\
(17.71)\end{array}$ \\
\hline
\end{tabular}

\begin{tabular}{lllll}
\hline SED & \multicolumn{1}{l}{ CD(0.05) } & $\mathrm{CD}(0.01)$ & & \\
Treatment & 0.30429 & 0.60659 & 0.80511 \\
Days 0.30429 & 0.60659 & 0.80511 & \\
Interaction & 0.74536 & 1.48584 & 1.97212
\end{tabular}

Values in parentheses indicate the concentration expressed as percentage of that present at the start of the experiment

different carbofuran degrading isolates are given in Table 2. A very good reduction in the carbofuran concentration was recorded in MSM inoculated with CF-7 (reduced to $17.71 \%$ ) followed by CF-1 (32.44
\%), CF-4 (41.99\%), CF-2 (47.20\%) and CF-3 (48.16\%). Growth of the isolates in the MSM and the reduction in carbofuran residue suggested that CF-7 (Bacillus sp.) obtained was the promising carbofuran

Table 3. Correlation coefficient values for the dissipation pattern of carbofuran with different carbofuran degrading bacterial isolates in the MSM

\begin{tabular}{|c|c|c|c|c|c|c|c|c|c|c|c|c|}
\hline \multirow{2}{*}{ Functions } & \multicolumn{2}{|c|}{ Control } & \multicolumn{2}{|c|}{$\mathrm{CF}-1$} & \multicolumn{2}{|c|}{ CF-2 } & \multicolumn{2}{|c|}{ CF-3 } & \multicolumn{2}{|c|}{$\mathrm{CF}-4$} & \multicolumn{2}{|c|}{ CF-7 } \\
\hline & $r$ & $\begin{array}{c}\text { Modified } \\
r^{2}\end{array}$ & $r$ & $\begin{array}{c}\text { Modified } \\
r^{2}\end{array}$ & $r$ & $\begin{array}{c}\text { Modified } \\
r^{2}\end{array}$ & $r$ & $\begin{array}{c}\text { Modified } \\
r^{2}\end{array}$ & $r$ & $\begin{array}{c}\text { Modified } \\
r^{2}\end{array}$ & $r$ & $\begin{array}{c}\text { Modified } \\
r^{2}\end{array}$ \\
\hline First order & $-0.99015^{\star *}$ & 0.97729 & -0.72932 & 0.53809 & $-0.96692^{* *}$ & 0.91440 & $-0.85834^{*}$ & 0.72106 & $-0.92557^{* *}$ & 0.84904 & -0.71330 & 0.47529 \\
\hline $1.5^{\text {th }}$ order & $0.99366^{* *}$ & 0.98353 & 0.73986 & 0.53863 & $0.97730^{\star *}$ & 0.92801 & $0.87563^{*}$ & 0.73661 & $0.93835^{\star *}$ & 0.86583 & 0.73748 & 0.45927 \\
\hline $2^{\text {nd }}$ order & $0.99620^{* *}$ & 0.98859 & 0.73946 & 0.52980 & $0.98530^{\star *}$ & 0.94107 & $0.89127^{\star}$ & 0.74852 & $0.95006^{* *}$ & 0.88084 & 0.76032 & 0.43183 \\
\hline RF First orde & $r-0.97853^{* *}$ & 0.95183 & $-0.89634^{*}$ & 0.85088 & $-0.99658^{* *}$ & 0.99413 & $-0.97314^{* *}$ & 0.95963 & $-0.97849^{* *}$ & 0.95327 & $-0.89607^{*}$ & 0.83474 \\
\hline RF $1.5^{\text {th }}$ orde & r $0.97259^{* *}$ & 0.93269 & $0.89897^{*}$ & 0.86537 & $0.99206^{\star *}$ & 0.98454 & $0.97795^{\star *}$ & 0.97231 & $0.97936^{* *}$ & 0.94741 & $0.90881^{*}$ & 0.84504 \\
\hline $\begin{array}{l}\text { RF Second } \\
\text { order }\end{array}$ & $0.96593^{* *}$ & 0.90622 & $0.90043^{*}$ & 0.87323 & $0.98546^{* *}$ & 0.96595 & $0.98093^{* *}$ & 0.98142 & $0.97906^{* *}$ & 0.93376 & $0.91923^{* *}$ & 0.84632 \\
\hline $\begin{array}{l}\text { Inverse } \\
\text { Power law }\end{array}$ & $0.96768^{* *}$ & -20.12140 & $0.81664^{*}$ & -9.25551 & $0.97225^{\star \star}-$ & -14.56301 & $10.97784^{* *}-$ & -15.00229 & $90.98554^{* *}$ & -8.45913 & $0.86842^{*}$ & -8.04797 \\
\hline
\end{tabular}


degrading isolate (Fig. 1). The carbofuran dissipation curve was found to be fit for the transformations viz. $2^{\text {nd }}$ order, for control; RF $1^{\text {st }}$ order, for CF-2 and CF-4 and RF second order for CF-1, CF-3 and CF-7 (Table 3 and Fig. 2). There was a reduction in half life of carbofuran from 16.76 days in control to 9.49 days with the isolate CF-7 (Table 4) in the experimental condition.

Venkateswarlu and Sethunathan (1984) isolated a bacterium which is able to use carbofuran as
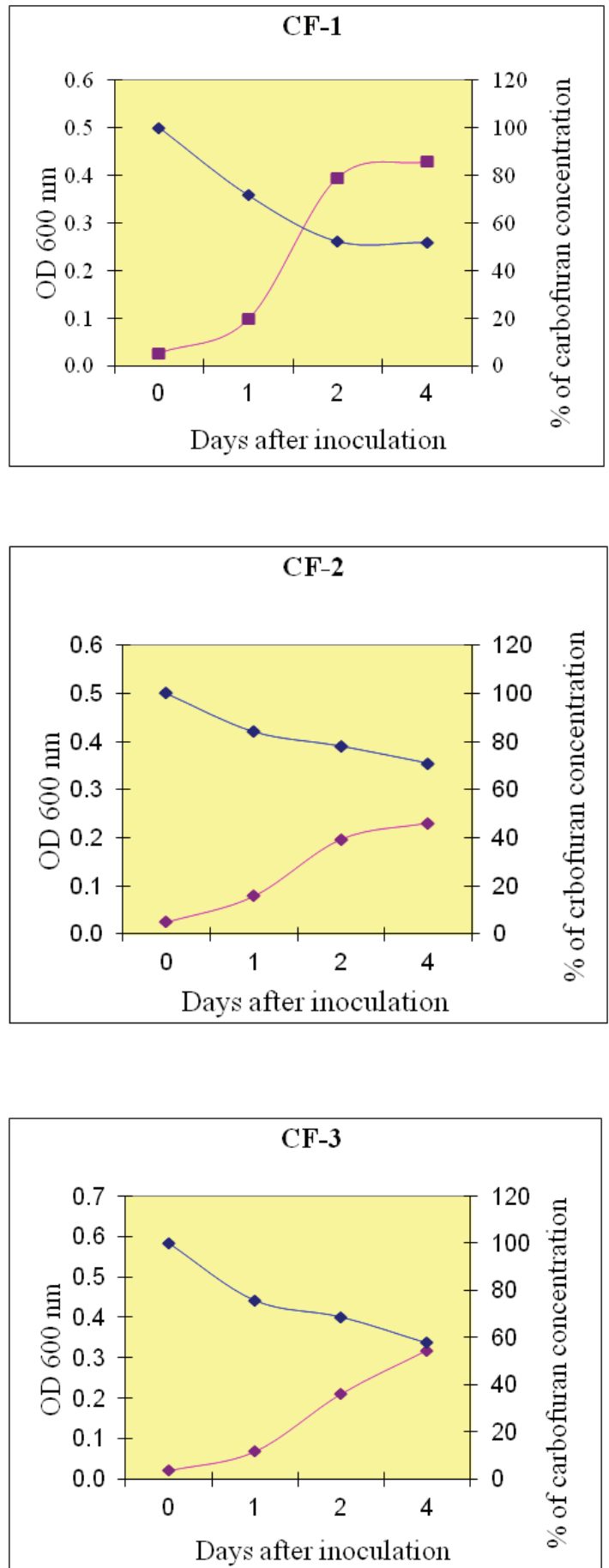
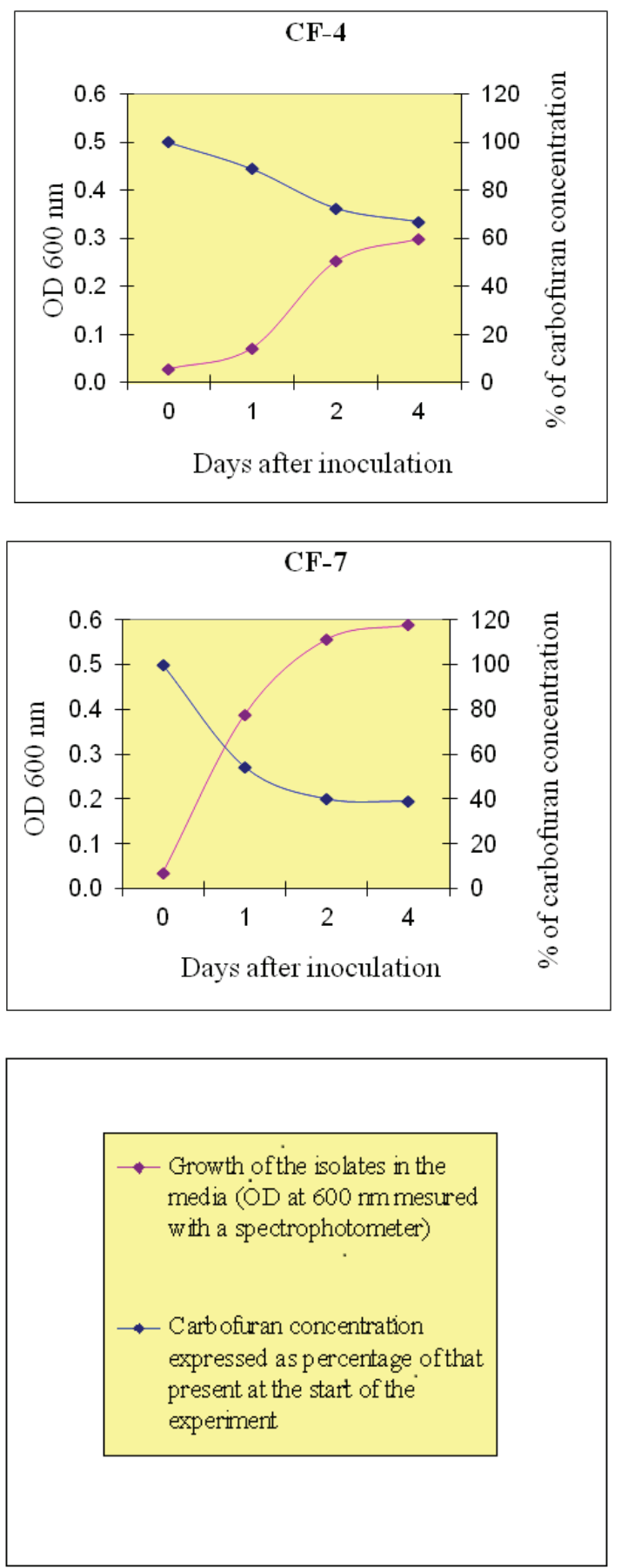

Fig. 1 Comparison of the growth and degradation potential of carbofuran degrading isolates in MSM provided with carbofuran as the sole source of carbon

a sole source of carbon. Rajagopal et al. (1984), isolated Bacillus sp., Micrococcus sp., Arthrobacter sp. and Azospirillum sp. capable of using carbofuran as a sole source of carbon and nitrogen, whereas, Karns et al. (1986) showed that carbofuran was only used as a sole source of nitrogen. Ramanand et al. (1988) isolated a bacterium tentatively identified as an Arthrobacter sp. from flooded soil. This bacterium exhibited an exceptional capacity to completely mineralize carbofuran within 72 to $120 \mathrm{~h}$ in a MSM 
as a sole source of carbon and nitrogen. Out of the fifteen bacterial isolates isolated by Chaudhry and Ali (1988), six utilized carbofuran as a sole source of
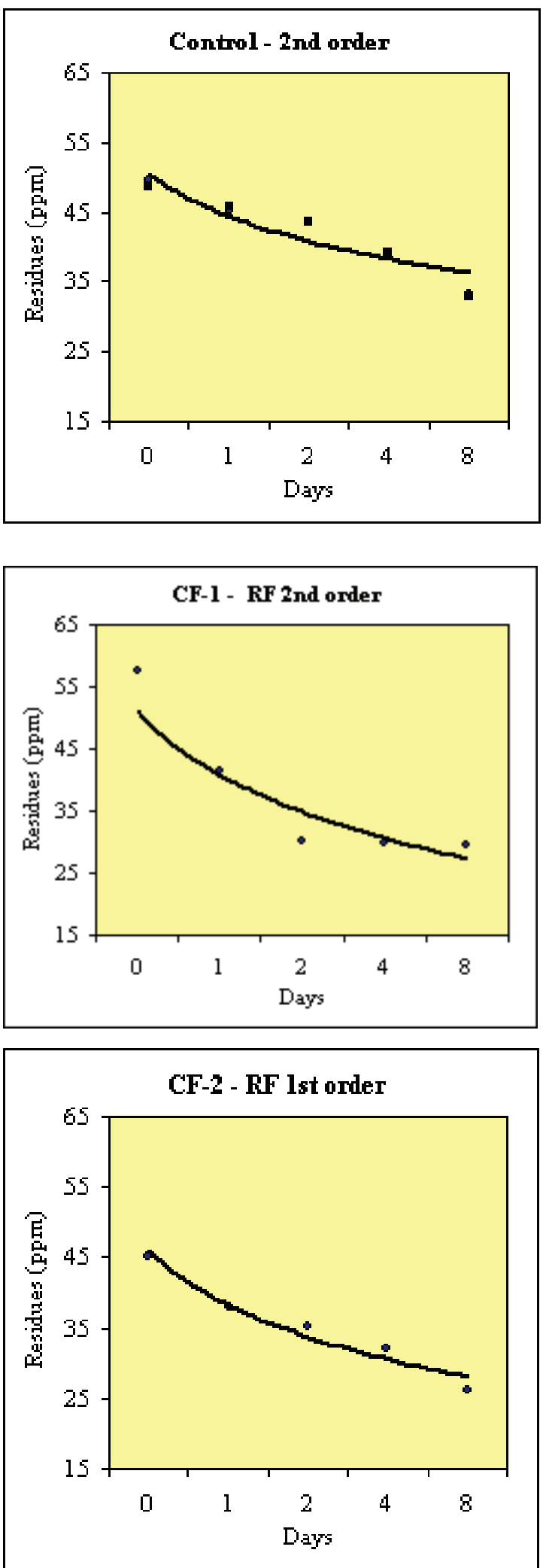
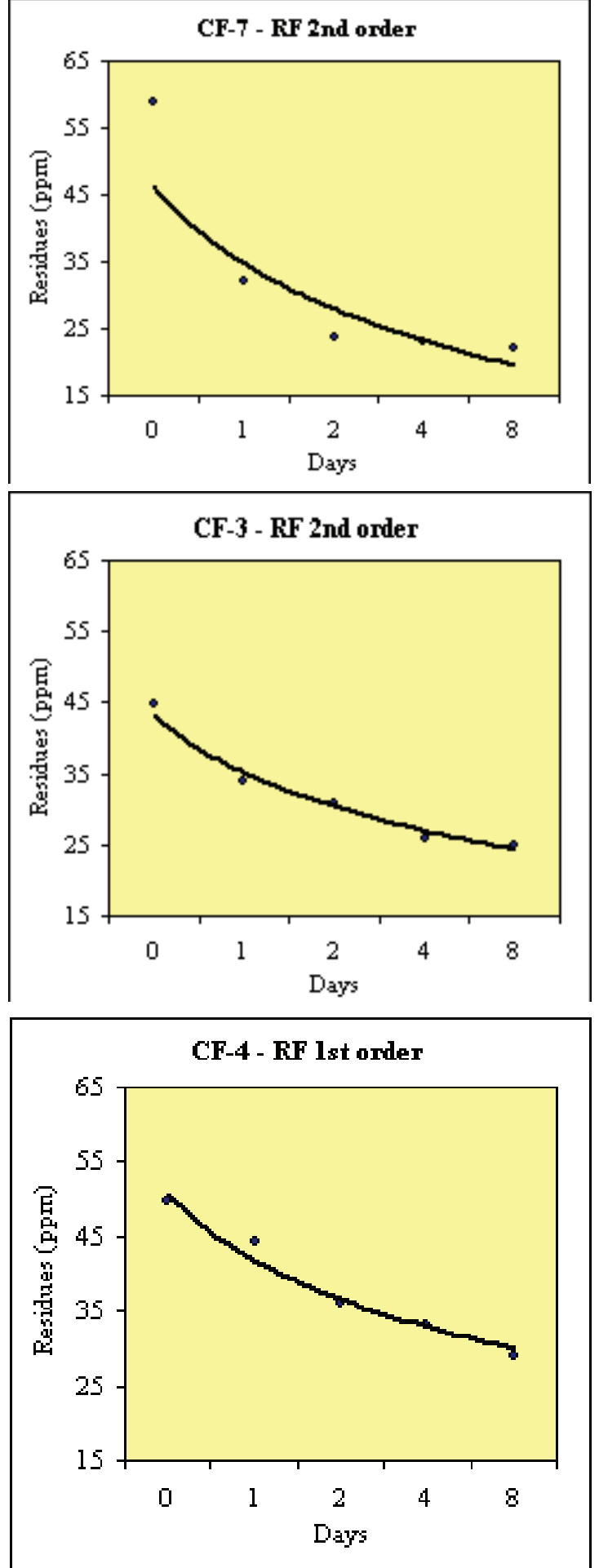

Fig. 2 Back transformed dissipation curve (best fit model) for carbofuran in MSM with different carbofuran degrading bacterial isolates

nitrogen, seven utilized carbofuran as a sole source of carbon and two isolates used carbofuran as the sole source of carbon and nitrogen. Slaoui et al. (2001) isolated a more potent bacterium (Pseudomonas $\mathrm{sp}$.) able to degrade carbofuran at a very high rate by using it as a sole source of nitrogen and carbon. All the above stated findings supported the present result of mineralization of carbofuran by soil bacteria in the artificial media. 
Table 4. Intercept, slope, half life and their confidence limit values for carbofuran degradation in artificial media with different carbofuran degrading bacterial isolates

\begin{tabular}{|c|c|c|c|c|c|c|c|}
\hline $\begin{array}{l}\text { Parameters with } \\
\text { confidence limit }\end{array}$ & & Control & CF-1 & CF-2 & CF-3 & CF-4 & CF-7 \\
\hline \multicolumn{2}{|l|}{ Function } & $2^{\text {nd }}$ order & $\begin{array}{l}\text { RF second } \\
\text { order }\end{array}$ & RF first order & $\begin{array}{l}\text { RF second } \\
\text { order }\end{array}$ & RF first order & $\begin{array}{l}\text { RF second } \\
\text { order }\end{array}$ \\
\hline \multirow{3}{*}{$\mathrm{K}_{1}(\mathrm{~b})$} & UL & 0.00216 & 0.03251 & -0.05321 & 0.01816 & 0.16619 & 0.07241 \\
\hline & & 0.00123 & 0.00627 & -0.18896 & 0.00668 & -0.20124 & 0.00811 \\
\hline & LL & 0.00030 & -0.01997 & -0.32470 & -0.00479 & -0.56868 & -0.05620 \\
\hline \multirow{3}{*}{$\mathrm{K}_{2}(\mathrm{a})$} & UL & 0.02334 & 0.05733 & 4.01866 & 0.03945 & 4.45385 & 0.35555 \\
\hline & & 0.02055 & 0.01932 & 3.82202 & 0.02283 & 3.92162 & 0.16263 \\
\hline & LL & 0.01777 & -0.01869 & 3.62538 & 0.00621 & 3.38938 & -0.03028 \\
\hline Modified $r^{2}$ & & 0.98859 & 0.87323 & 0.99413 & 0.98142 & 0.95327 & 0.84632 \\
\hline $\mathrm{T}_{0.5} \cdot{ }^{*}$ & & 16.76 & 10.20 & 12.75 & 12.94 & 12.52 & 9.49 \\
\hline
\end{tabular}

RF-Root Function; UL-Upper Limit; LL-Lower Limit; $\mathrm{K}_{1}(\mathrm{a})$-Intercept; $\mathrm{K}_{2}(\mathrm{~b})$-Slope

* To get the uniformity and for the better comparison of the reduction in half life due to the action of different isolates, half life alone was calculated in $2^{\text {nd }}$ order function (best fit model for the control) for all the isolates.

From the results obtained in this study, the Bacillus subtilis (CF-7) isolated from the enrichment culture was found to be potent in reducing the concentration of carbofuran. This opened the possibility for utilizing the above isolate in bioremediation study. This study has some practical benefits also regarding the detoxification of soil with highly persistent pesticides.

\section{References}

Chaudhry, G. R. and Ali, A. N. 1988. Bacterial metabolism of carbofuran. Appl. Environ. Microbiol., 54: 1414 - 1419.

Chaudhry, G. R., Mateen, A., Kaskar, B., Sardessai, M., Bloda, M., Bhatti, A. R. and Walia, S. K. 2002. Induction of carbofuran oxidation to 4-hydroxycarbofuran by Pseudomonas sp. 50432. FEMS Microbiol. Lett., 214(2): 171-176.

Fahmy, M.A., Fukuto, T. R., Myers, R.O. and March, R.B. 1970. The selective toxicity of -phosphorothioethylcarbamate esters. J. Agric. Food Chem., 18: 793-796.

Farahani, G. H. N., Zakaria, Z., Kuntom, A., Omar, D. and Ismail, B. S. 2007. Absorbtion and desorption of carbofuran in malayan soil. Advances in Environmental Biology, 1(1): 20-26.

Karns, J. S., Mulbry, W. W., Nelson, J. O. and Kearney, P. C. 1986. Metabolism of carbofuran by a pure bacterial culture. Pesticide Biochem. Physiol., 25: 211-217.

Kohout, F. J. 1974. Statistics for Social Scientists. John Wiley and Sons, Inc., New York. 27p.

Nafeesa. M. 2009, Studies on Bacterial Degradation of Chlorpyriphos and Carbofuran Residues Using Potential Strains Isolated from the Pretreated Soils M.Sc.(Ag) Thesis, Tamil Nadu Agricultural University, Coimbatore. $p: 57$.

Nigg, H.N. and Stamper, J.H. 1980. Persistence of henthoate (Cidial) and phenthoate oxon on fruit, leaf and soil surfaces and in air in Florida citrus. Chemosphere, 9: 343-350.
Panse, V. G. and Sukhatmae. P. V. 1985. Statistical Methods for Agricultural Workers. IV Ed. Indian Council of Agrl. Research, New Delhi.

Rajagopal, B. S., Rao, V.R., Nagendrappa, G. and Sethunathan, N. 1984. Metabolism of carbaryl and carbofuran by soil enrichment and bacterial cultures. Can. J. Microbiol., 30: 1458-1466.

Ramanand, K., Sharmila, M. and Sethunathan, N. 1988. Mineralization of carbofuran by a soil bacterium. Appl. Environ. Microbiol., 54: 2129-2133.

Regupathy, A. and K. P. Dhamu. 2001. Statistics Workbook for Insecticide Toxicology. Softeck Computers, Coimbatore. 206p.

Singh, B.K., Walker, A., Morgan, J.A.W. and Wright. D. J. 2004. Biodegradation of chlorpyriphos by Enterobacter strain B-14 and its use in bioremediation of contaminated soil. Appl. Environ. Microbiol., 70: 4855-4863.

Slaoui, M., Uhssine, M., Berny. E. and Elyachioui. M. 2007. Biodegradation of the Carbofuran by a fungus isolated from treated soil, African J. Biotechnology, 6 (4): 419-423.

Talebi, K. and Walker, C.H. 1993. A comparative study of carbofuran metabolism in treated and untreated soils, Pestic. Sci., 39(11): 65-69.

Timme, G., Frehse, H. and V. Laska. 1986. Statistical interpretation and graphic representation of the degradational behaviour of pesticide residues-II. Pflanzenschutz-Nachrichten Bayer, 39: 189-203.

Venkateswarlu, K. and N. Sethunathan. 1984. Degradation of carbofuran by Azospirillum lipoferum and Streptomyces spp. isolated from flooded alluvial soil, Bull. Environ. Cont. Toxicol., 33: 556-560.

Yan, Q. X., Hong, Q., Han, P., Dong, X.J., Shen, Y.J. and Li S.P. 2007. Isolation and characterization of a carbofuran-degrading strain Novosphingobium sp. FND-3, FEMS Microbiol Lett., 271(2):207-13. 